\title{
Assessment of the quality of end-of-life care: translation and validation of the German version of the "Care of the Dying Evaluation" (CODE-GER) - a questionnaire for bereaved relatives
}

Annika Vogt ${ }^{1 \dagger}$, Stephanie Stiel ${ }^{2 \dagger}$, Maria Heckel ${ }^{3}$, Swantje Goebel ${ }^{1}$, Sandra Stephanie Mai ${ }^{1}$, Andreas Seifert ${ }^{4}$, Christina Gerlach ${ }^{1}$, Christoph Ostgathe ${ }^{3}$ and Martin Weber ${ }^{1 *}$ (D)

\begin{abstract}
Background: International studies indicate deficits in end-of-life care that can lead to distress for patients and their next-of-kin.

The aim of the study was to translate and validate the "Care of the Dying Evaluation" (CODE) into German (CODE-GER).

Methods: Translation according to EORTC (European Organisation for Research and Treatment of Cancer) guidelines was followed by data collection to evaluate psychometric properties of CODE-GER. Participants were next-of-kin of patients who had died an expected death in two hospitals. They were invited to participate at least eight, but not later than 16 weeks after the patient's death. To calculate construct validity, the Palliative care Outcome Scale (POS) was assessed. Difficulty and perceived strain of answering the questionnaire were assessed by a numeric scale (0-10).

Results: Out of 1137 next-of-kin eligible, 317 completed the questionnaire (response rate: 27.9\%). Data from 237 main sample participants, 38 interraters and 55 next-of-kin who participated for repeated measurement were analysed. Overall internal consistency, $a=0.86$, interrater reliability, ICC $(1)=0.79$, and retest-reliability, ICC $(1,2)=0.85$, were good. Convergent validity between POS and CODE-GER, $r=-.46$, was satisfactory. A principal component analysis with varimax rotation showed a 7-factor solution. Difficulty, $M=2.2 ; \mathrm{SD} \pm 2.4$, and perceived strain, $\mathrm{M}=4.1 ; \mathrm{SD} \pm 3.0$, of completing the questionnaire were rather low.
\end{abstract}

Conclusion: The results from the present study confirm CODE-GER as a reliable and valid instrument to assess the quality of care of the dying person. More over our study adds value to the original questionnaire by proposing a deepened analysis of obtained data. The development of seven subscales increases its potential for further surveys and research.

(Continued on next page)

\footnotetext{
* Correspondence: Martin.Weber@unimedizin-mainz.de

${ }^{\dagger}$ Annika Vogt and Stephanie Stiel contributed equally to this work.

'Interdisciplinary Palliative Care Unit, III. Department of Medicine, University

Medical Center of the Johannes Gutenberg University of Mainz,

Langenbeckstr.1, 55131 Mainz, Germany

Full list of author information is available at the end of the article
}

C C The Author(s). 2020 Open Access This article is licensed under a Creative Commons Attribution 4.0 International License, which permits use, sharing, adaptation, distribution and reproduction in any medium or format, as long as you give appropriate credit to the original author(s) and the source, provide a link to the Creative Commons licence, and indicate if changes were made. The images or other third party material in this article are included in the article's Creative Commons licence, unless indicated otherwise in a credit line to the material. If material is not included in the article's Creative Commons licence and your intended use is not permitted by statutory regulation or exceeds the permitted use, you will need to obtain permission directly from the copyright holder. To view a copy of this licence, visit http://creativecommons.org/licenses/by/4.0/. The Creative Commons Public Domain Dedication waiver (http://creativecommons.org/publicdomain/zero/1.0/) applies to the data made available in this article, unless otherwise stated in a credit line to the data. 
(Continued from previous page)

Trial registration: This study was registered retrospectively on the 25th of January 2018 at the German Clinical Trials Register (DRKS00013916).

Keywords: Terminal care, Quality of health care, Proxy, Hospital, Validation studies, outcome assessment

\section{Background}

According to the founder of modern palliative care (PC) Cicely Saunders, physical, psychological, social and spiritual needs have to be considered when caring for dying patients and their families [1]. Despite the clear need for PC, not all dying patients can be treated on specialized wards due to limited access or space $[2,3]$. Therefore, it is of great importance to extend the principles of PC to any wards where people die.

It is equally important to assess the current state of quality of care (QOC) on these wards, and to identify unmet needs of patients and their next-of-kin. While the patients themselves are often unable to provide information about the perceived quality of their care, their nextof-kin can evaluate the last days of their loved ones [4]. They are not only providers of support to the patients, but also recipients of PC themselves [5]. Therefore an instrument which assesses the care given to the patient, but also to their next-of-kin, is crucial to represent holistic care at the end of life. To the best of our knowledge the only instrument that assesses a similar construct in German is the "Quality of Death and Dying" (QoDD) which was validated by some of this study's authors [6]. However, QoDD surveys the quality of death and not the quality of care given to the dying patient.

A suitable instrument for this purpose, the "Care of the Dying Evaluation" $\left(\mathrm{CODE}^{\mathrm{Tm}}\right)$ was developed by selecting key indicators from the rather long "Evaluation Care and Health Outcomes - for the Dying" (ECHO-D) [7]. $\mathrm{CODE}^{\mathrm{Tx}}$ is a self-assessment questionnaire which retrospectively evaluates the QOC in the last 2 days of a patient's life by surveying next-of-kin. Twenty-eight core items cover different aspects of QOC (care received from healthcare team, symptom control, communication with the healthcare team, emotional and spiritual support, circumstances surrounding death). Verbal anchors represent a 5-point $(0-4), 4$-point $(0-3)$ or 3-point $(0-2)$ Likert scale. The higher the value, the better the QOC [7]. Three key composite scales which are represented by 12 of the 28 core items, survey "Environment", "Care" and "Communication". The items were initially assigned to the scales based on theoretical assumptions. Furthermore, $\mathrm{CODE}^{\mathrm{m}}$ captures overall impression concerning treatment with respect and dignity by doctors and nurses as well as support of relatives. Ten items assess demographic or disease-related information [7].
$\mathrm{CODE}^{\mathrm{ma}}$ has so far been validated for the United Kingdom [7]. Internal consistencies of the key composite scales were good $(\alpha=0.79-0.89)$. Test-retest-reliability was moderate to good [7]. A recent systematic review on tools measuring quality of death, dying and care completed after death identified $\mathrm{CODE}^{\mathrm{m}}$ as an instrument with promising strong psychometric properties, which would benefit from further development and validation [8].

\section{Methods}

The aim of this study was to provide a German version of $\mathrm{CODE}^{\mathrm{Tm}}$ (CODE-GER) and to evaluate its psychometric properties.

\section{Translation process, pretesting and questionnaire adaption}

Between 01/2013 and 04/2013, $\operatorname{CODE}^{\mathrm{TM}}$ was translated forward and backward according to EORTC guidelines [9]. To assess content validity, 'think aloud' interviews and verbal probing took place with 15 next-of-kin of deceased patients at 2 PC units (Mainz: $n=7$; Erlangen: $n=8$ ). Results from this pilot testing were discussed by an expert panel with expertise in PC. No items were evaluated as inappropriate, confusing or embarrassing. The questionnaire itself was rated as useful. Adaptions to the wording and formal structure were made. The 28 core items on QOC were maintained without modification. One item (recommendability of ward) was added to the overall section (originally three items). The 28 core items on QOC as well as the overall impression questions are shown in Table 1. Three items (type of ward, nationality of caregiver, amount of days on the ward where the patient had died) were added to the demographic section (originally 10 items compared to the original English version). The items of the resulting questionnaire CODE-GER used in this study are shown in Table 1.

After completing the CODE-GER, participants additionally were asked to give the time they needed to fill in the questionnaires and one question on the difficulty and the perceived strain of completing the questionnaire. They used a scale from 0 (very easy/no strain) to 10 (very hard/high strain). Although these questions have not yet been validated formally they have been used in previous studies [10-12]. 
Table 1 CODE GER - items included in psychometric analyses and overall impression questions

\begin{tabular}{ll}
\hline Item CODE & Short Description \\
\hline $\begin{array}{l}\text { There was enough help available to meet } \\
\text { his/her personal care needs, such as }\end{array}$ & Nursing care- personal care need \\
washing, personal hygiene and toileting & \\
needs. & \\
$\begin{array}{l}\text { There was enough help with nursing care, } \\
\text { such as giving medicines and helping }\end{array}$ & $\begin{array}{l}\text { Nursing care - medicines and } \\
\text { him/her find a comfortable position }\end{array}$
\end{tabular}

in bed.

The bed area and surrounding environment was comfortable for him/her.

The bed area and surrounding environment had adequate privacy for him/her.

In your opinion, how clean was the ward area that $s /$ he was in? ${ }^{a}$

Did you have confidence and trust in the nurses who were caring for him/her?

Did you have confidence and trust in the doctors who were caring for him/her?

The nurses had time to listen and discuss his/her condition with me.

The doctors had time to listen and discuss his/her condition with me.

In your opinion, during the last 2 days, did s/he appear to be in pain?

In your view, did the doctors and nurses do enough to help relieve the pain?

In your opinion, during the last 2 days, did $s /$ he appear to be restless?

In your opinion, did the doctors and nurses do enough to help relieve the restlessness?

In your opinion, during the last 2 days, did s/he appear to have a 'noisy rattle' to his/her breathing?
Whether the bed area had adequate privacy

Whether ward was clean

Confidence and trust in nurses

Confidence and trust in doctors

Time of nurses to listen and discuss the patients' condition

Time of doctors to listen and discuss the patient's condition

Whether patient had pain

Whether HCT did all they could to relieve pain

Whether patient was restless

Whether HCT did all they could to relieve restlessness

Whether patient had retained respiratory tract secretions
Verbal Anchors and Rating Scale

$0=$ strongly disagree

$1=$ disagree

$2=$ neither agree nor disagree

$3=$ agree

$4=$ strongly agree

$0=$ strongly disagree

$1=$ disagree

$2=$ neither agree nor disagree

$3=$ agree

$4=$ strongly agree

$0=$ strongly disagree

$1=$ disagree

$2=$ neither agree nor disagree

3 = agree

4 = strongly agree

$0=$ strongly disagree

$1=$ disagree

$2=$ neither agree nor disagree

$3=$ agree

$4=$ strongly agree

$0=$ Not at all clean

$2=$ Fairly clean

$4=$ Very clean

$0=$ No, not in any of the nurses

$2=Y e s$, in some of them

$4=$ Yes, in all of them

$0=\mathrm{No}$, not in any of the doctors

$2=Y e s$, in some of them

$4=$ Yes, in all of them

$0=$ strongly disagree

$1=$ disagree

$2=$ neither agree nor disagree

$3=$ agree

$4=$ strongly agree

$0=$ strongly disagree

$1=$ disagree

$2=$ neither agree nor disagree

$3=$ agree

$4=$ strongly agree

$0=Y e s$, all of the time

$2=$ Yes, some of the time

$4=\mathrm{No}$

$0=$ No, not at all

$2=$ Yes, some of the time

$4=$ Yes, all of the time

$4=$ Not applicable, s/he was

not in pain

$0=$ Yes, all of the time

$2=$ Yes, some of the time

$4=\mathrm{No}$

$0=$ No, not at all

$2=$ Yes, some of the time

$4=$ Yes, all of the time

$4=$ Not applicable, s/he was

not restless

$0=$ Yes, all of the time

$2=$ Yes, some of the time

$4=\mathrm{No}$ 
Table 1 CODE GER - items included in psychometric analyses and overall impression questions (Continued)

\begin{tabular}{ll}
\hline Item CODE & Short Description \\
\hline In your view, did the doctors and nurses & Whether HCT did all they could to \\
do enough to help relieve the 'noisy rattle' & control respiratory tract secretions
\end{tabular}

do enough to help relieve the 'noisy rattle' to his/her breathing?

During the last 2 days, how involved were you with the decisions about his/her care and treatment?

Did any of the healthcare team discuss with you whether giving fluids through a 'drip' would be appropriate in the last 2 days of life?

Would a discussion about the appropriateness of giving fluids through a 'drip' in the last 2 days of life have been helpful?

Did the healthcare team explain his/her condition and/or treatment in a way you found easy or difficult to understand?

How would you assess the overall level of emotional support given to you by the healthcare team?

Overall, his/her religious or spiritual needs were met by the healthcare team.

Overall, my religious or spiritual needs were met by the healthcare team.

Before $s /$ he died, were you told $s /$ he was likely to die soon?

Did a member of the healthcare team talk to you about what to expect when s/he was dying (e.g. symptoms that may arise)?

Would a discussion about what to expect when s/he was dying have been helpful?

In your opinion did s/he die in the right place? ${ }^{a}$

I was given enough help and support by the healthcare team at the actual time of his/her death

After s/he had died, did individuals from the healthcare team deal with you in a sensitive manner?

\section{Overall Impression}

How much of the time was s/he treated
Involvement in decision-making

Whether discussion of giving fluids through a 'drip' took place

Whether discussion giving fluids through a 'drip' would have been helpful

Difficulty of explanations of the patient's condition

Emotional support to next-of-kin

Whether HCT met overall religious spiritual needs of patient

Whether HCT met overall religious spiritual needs of next-of-kin

Information about the soon death of the patient

Information about what to expect during the dying process of the patient

Whether a discussion about what to expect during the dying process would have been helpful

Whether patient died in the right place

Support at actual time of death

Sensitivity of HCT after death

Whether patient was treated with
$0=$ No, not at all

$2=$ Yes, some of the time

$4=Y e s$, all of the time

$4=$ Not applicable, $s /$ he had

no noisy rattle

$0=$ Not involved

$2=$ Fairly involved

$4=$ Very involved

$0=\mathrm{No}$

$4=$ Yes

$0=$ Yes

$4=\mathrm{No}$

$4=$ Not applicable, we had these type of discussions

$0=$ They did not explain his/her condition or treatment to me $1=$ Very difficult

$2=$ Fairly difficult

$3=$ Fairly easy

$4=$ Very easy

$0=$ Poor

$1=$ Fair

$3=$ Good

$4=$ Excellent

$0=$ strongly disagree

$1=$ disagree

$2=$ neither agree nor disagree

$3=$ agree

$4=$ strongly agree

$0=$ strongly disagree

$1=$ disagree

$2=$ neither agree nor disagree

$3=$ agree

$4=$ strongly agree

$0=$ No

$4=$ Yes

$0=\mathrm{No}$

$4=$ Yes

$0=\mathrm{No}$

$4=$ Yes

$4=$ Not applicable, we had

these types of discussions

$0=\mathrm{No}$, it was not the right place

$2=$ Not sure

$4=$ Yes, it was the right place

$0=$ strongly disagree

$1=$ disagree

$2=$ neither agree nor disagree

$3=$ agree

$4=$ strongly agree

$0=\mathrm{No}$

$4=$ Yes 
Table 1 CODE GER - items included in psychometric analyses and overall impression questions (Continued)

\begin{tabular}{|c|c|c|}
\hline Item CODE ${ }^{\mathrm{TM}}$ & Short Description & Verbal Anchors and Rating Scale \\
\hline $\begin{array}{l}\text { with respect and dignity in the last } \\
2 \text { days of life by doctors? }\end{array}$ & respect and dignity by doctors & $\begin{array}{l}1=\text { Some of the time } \\
3=\text { Most of the time } \\
4=\text { Always }\end{array}$ \\
\hline $\begin{array}{l}\text { How much of the time was s/he treated } \\
\text { with respect and dignity in the last } \\
2 \text { days of life by nurses? }\end{array}$ & $\begin{array}{l}\text { Whether patient was treated with } \\
\text { respect and dignity by nurses }\end{array}$ & $\begin{array}{l}0=\text { Never } \\
1=\text { Some of the time } \\
3=\text { Most of the time } \\
4=\text { Always }\end{array}$ \\
\hline $\begin{array}{l}\text { Overall, in your opinion, were you } \\
\text { adequately supported during his/her } \\
\text { last } 2 \text { days of life? }\end{array}$ & $\begin{array}{l}\text { Whether next-of-kin was } \\
\text { adequately supported }\end{array}$ & $\begin{array}{l}0=\mathrm{No} \\
4=\text { Yes }\end{array}$ \\
\hline $\begin{array}{l}\text { How likely are you to recommend our } \\
\text { ward to friends and family? }\end{array}$ & $\begin{array}{l}\text { Whether next-of-kind would } \\
\text { recommend ward to family/friends }\end{array}$ & $\begin{array}{l}0=\text { Extremely unlikely } \\
1=\text { Unlikely } \\
2=\text { Neither likely nor unlikely } \\
3=\text { Likely } \\
4=\text { Extremely likely }\end{array}$ \\
\hline
\end{tabular}

${ }^{a}=$ Item was deleted after psychometric analyses for the final version of CODE-GER

\section{Study population and data collection}

The study was conducted at the two German university hospitals of Mainz (MZ) and Erlangen (E) on the following types of ward: intensive care, palliative care, internal medicine and neurology. A minimum number of 200 next-of-kin were planned to be included, as recommended for psychometric testing by Lienert and Raatz [13].

All consecutive patients who had died on these wards between 04/2016 and 03/2017 were included according to the following eligibility criteria:

(a) $\geq 18$ years old

(b) stay $\geq 3$ days on the ward where death occurred,

(c) expected death, based on physician's judgment that the patient was soon to die, and the cause of death was not sudden.

To identify eligible patients, databases of all deaths on the predefined wards were electronically screened for criteria (a) and (b). Next, the responsible physicians were contacted personally to check for criterion (c). Next-of-kin data of patients were extracted from the electronic hospital information system. If more than one next-of-kin was registered, all of them were contacted to assure an inter-rater-population. Eligible nextof-kin were informed about the study and invited to take part by post at least eight, but not later than 16 weeks after the death. Next-of-kin were defined as family, friends or legal guardian. Through a postcard, which was sent to next-of kin, next-of-kin were able to inform the study team whether they wished to receive study information. If the corresponding box was ticked, a trained researcher phoned the next-of-kin to provide them with further information and to check for the following exclusion criteria: Under 18 years old; insufficient German language skills; no contact with patient in the last 2 days of life.

Eligible next-of-kin were asked whether they felt emotionally stable enough to participate in the study. After consent was given verbally over the phone, the study documents (detailed study information, informed consent form, CODE-GER, Palliative care Outcome Scale (POS) and a prepaid envelope) were sent to participants (T1). Participants were asked to tick a box on the informed consent form to indicate if they would be willing to repeat the survey (T2). Those who agreed received a second study pack 8 weeks after the first documents were completed. To determine interrater reliability, this first next-of-kin group was asked to provide contact details for additional relatives present during the last 2 days of the patient's life. Additional next-of-kin underwent the same recruitment process as the first next-of-kin group, although the latter were called directly if phone numbers were provided.

\section{Description of questionnaires}

All participants were asked to complete CODE-GER. In addition, participants completed the Palliative Care Outcome Scale (POS) for families. As there is no German instrument available regarding equivalent content, the content wise comparable tool POS (available as a validated German version) was chosen to allow for an approximate external criterion, since it assesses the convergent validity of CODE to some extent. POS is a 12-item self-assessment instrument that surveys for symptoms, concerns and psychosocial needs of patient and family in the past 3 days of the patient's life. Answers are scored on a 0-4 Likert scale. Scores of items 1-10 can be summarized into a Total-Score (0-40). Higher scores are associated with higher distress [10]. 


\section{CODE-GER items and Total-score}

Verbal anchors provided in the answering possibilities represent a 5-point (0-4), 4-point (0-3) or 3-point (0-2) Likert scale. In order to establish a unified rating scale from "0" to " 4 ", the following rules were defined: the highest possible answer, indicating high quality, was coded with "4", while "0" was assigned to the lowest. Middle categories were represented by "2" (for more details see Table 1 ).

For further analysis values of single items were summed up according to their respective subscales. Next, these values were added up to form a TotalScore (0-104). A high Total-Score corresponds to high quality end-of-life care.

Items with more than $50 \%$ of missing values across all questionnaires were excluded from further analysis [14]. To minimize the effect of imputation, a maximum of $15 \%$ of missing items was tolerated and imputed by Expectation Maximization for interval variables per questionnaire [15]. Questionnaires with more than 15\% missings were excluded from further analysis. Missing values for dichotomous variables were imputed by the mode of the corresponding item to ensure conformity with the rating scale.

\section{Data analysis \\ Psychometric properties}

Since only 12 of the 28 core items of the original CODE TM questionnaire have been examined by factor analytic methods so far, we analyzed the 28 core items on QOC with an explorative factor analysis. In order to explain as much variance as possible in the data we conducted a principal component analysis (PCA) with varimax rotation. To test whether our data were suitable for PCA the Bartlett's test and Kaiser-Meyer-Olkin Measure of Sampling Adequacy were carried out. The number of factors was determined by the Kaiser-Guttmann criterion (eigenvalues $>1$ ), analysis of the scree plot and conceptual fit $[16,17]$.

\section{Inclusion of items}

Decisions on the assignment of items to a factor were based on the following criteria:

a) higher Cronbach's alpha if item was included (concerning the subscale)

b) item to total correlation $\geq 0.4$ [18]

c) factor loading $\geq 0.3$ [19]

d) items that only load on one factor

e) consistency between the item and the content of the factor

All criteria should be met. In doubtful cases criterion e) was pivotal.

\section{Reliability}

Internal consistency was measured with Cronbach's alpha [20]. Values $\geq 0.7$ are regarded as satisfactory [21].

Interrater reliability was calculated with intraclass correlation (ICC) estimates and their 95\% confidence intervals (CI) for Total-Scores, based on a one-way random model (ICC (1)). For test-retest reliability, ICC was calculated with Total-Scores of $\mathrm{T} 1$ and $\mathrm{T} 2$ with a single rating, absolute agreement, two-way mixed-effects model (ICC $(1,2))[22,23]$. An ICC $<0.5$ indicated poor reliability, $0.5-0.75$ moderate, $0.75-0.9$ good and $>0.9$ excellent [24].

\section{Validity}

Construct validity was assessed with convergent validity by a Pearson's correlation coefficient between the TotalScores of CODE-GER and POS. As low values in POS are associated with low distress, a negative correlation was expected.

\section{Items of overall impression}

To examine if items of overall impression (Table 1) represented the Total-Score, Pearson's ( $r$ ) or Spearman's rank (rs) correlations were calculated according to the rating scale of the item. Correlations $\leq 0.3,>0.3,>0.7$ are regarded as low, moderate and high, respectively [25].

\section{Recruitment and demographic and disease-related information}

Data on the recruitment of the study population and their demographic and disease-related information as well as the time needed to answer the CODE-GER were analyzed using descriptive statistics and frequency analysis.

All statistical analyses were performed using IBM SPSS Statistics 23 for Windows [26].

\section{Results}

Study population and data collection

A total of 1714 patients died during the recruitment period. According to criteria a-c 750 patients were excluded. Fifty patients and their next-of-kin dropped out before first contact. Eventually, 1137 next-of-kin were invited to participate in the study, comprising 914 next-of-kin initially contacted, and 223 additional nextof-kin. Before phone screening, 704 dropped out. During the screening, 33 next-of-kin declined participation, and 14 were excluded. Eventually, 317 of 386 eligible and approachable next-of-kin returned the study documents (overall response rate: 27.9\%). For statistical analysis 42 cases were excluded. As a consequence of deleting cases of first measurement, seven cases of repeated measurement were excluded, leaving 55 out of 62 completed questionnaires for repeated measurement analysis. The main sample consisted of 237, the 


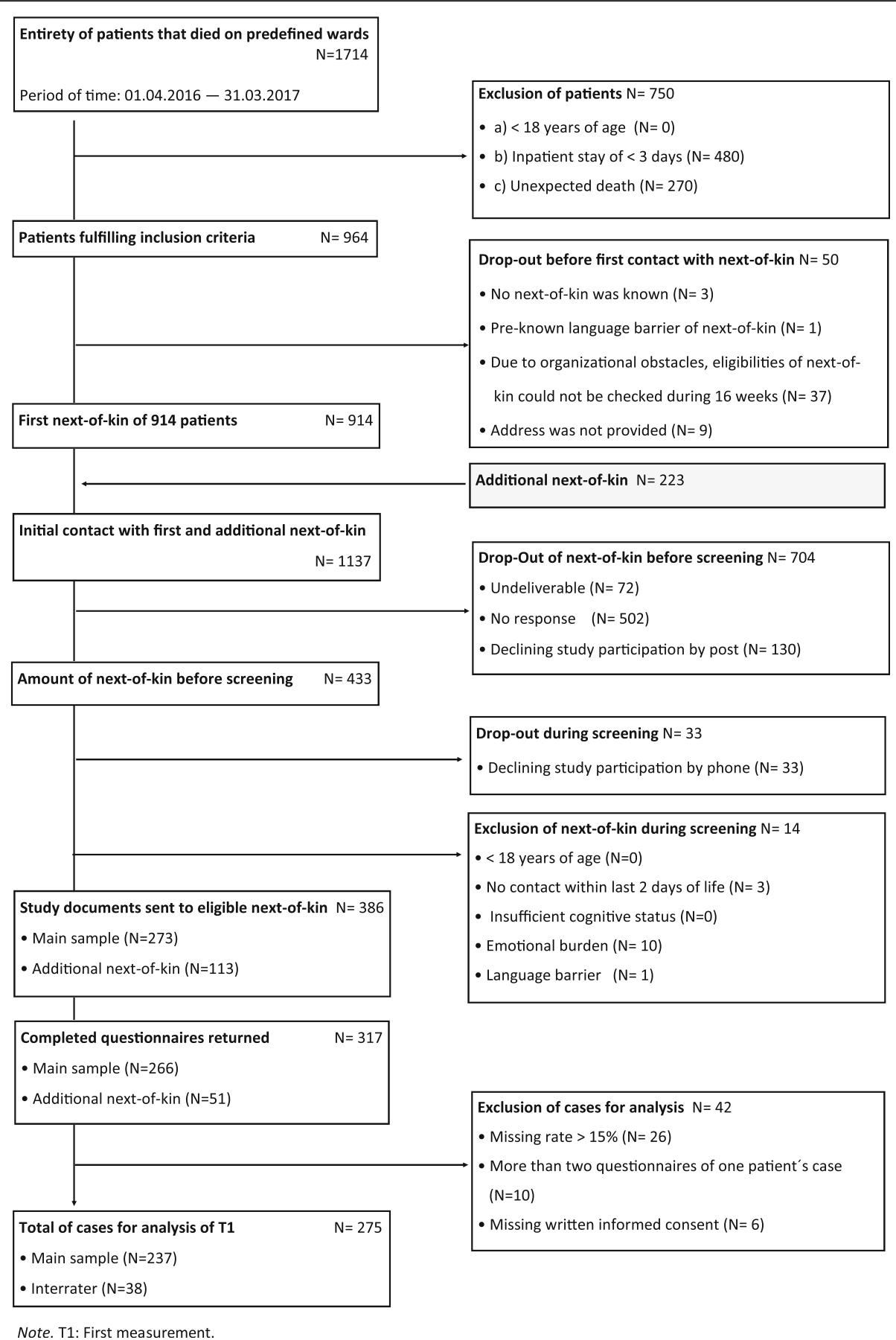

Fig. 1 Flow-chart for study partcipation

interrater group of 38 participants. Details of data collection including reasons for drop out and exclusion are shown in the flow chart of study participation (Fig. 1).

\section{Characteristics}

Most participants were between 50 and 59 (29\%) and 60 and $69(24 \%)$ years, 65\% were female. Most participants were either "husband/wife/partner" (43\%) or "son/daughter" (41\%). In total, 213 (90\%) were German with no migrant background. As for religion, $81 \%$ were Christians, $0.5 \%$ were New Apostolic, and 18\% had no religious affiliation. The most common diagnosis of the deceased patients was cancer (57\%). The average length of inpatient stay was 13.7 days $(\mathrm{SD} \pm 21.1$; range $=3-$ 276). Further subject characteristics are presented in Table 2. 
Table 2 Characteristics of next-of-kin and information about patients

\begin{tabular}{|c|c|c|c|}
\hline & Main sample $(N=237)$ & Interrater $(N=38)$ & $\mathrm{T} 2(N=55)$ \\
\hline & Number (\%) & Number (\%) & Number (\%) \\
\hline \multicolumn{4}{|l|}{ Gender } \\
\hline Female & $153(65)$ & $27(71)$ & $36(66)$ \\
\hline Male & $84(35)$ & $11(29)$ & $19(34)$ \\
\hline \multicolumn{4}{|l|}{ Age } \\
\hline $20-29$ & $6(3)$ & $4(11)$ & $2(4)$ \\
\hline $30-39$ & $20(8)$ & - & $5(9)$ \\
\hline $40-49$ & $34(14)$ & $10(26)$ & $10(18)$ \\
\hline $50-59$ & $69(29)$ & $15(40)$ & $17(31)$ \\
\hline $60-69$ & $56(24)$ & $5(13)$ & $15(27)$ \\
\hline $70-79$ & $33(14)$ & $2(5)$ & $5(9)$ \\
\hline $80+$ & $19(8)$ & $2(5)$ & $1(2)$ \\
\hline \multicolumn{4}{|l|}{ Relation to patient } \\
\hline Husband / Wife / Partner & $101(43)$ & $11(30)$ & $21(38)$ \\
\hline Son / Daughter & $96(41)$ & $15(39)$ & $23(42)$ \\
\hline Brother / Sister & $13(6)$ & $4(10)$ & $3(5)$ \\
\hline Son-in-law / Daughter-in-law & $4(2)$ & $6(16)$ & $2(4)$ \\
\hline Parent & $9(3)$ & - & $1(2)$ \\
\hline Friend & $3(1)$ & - & - \\
\hline Other & $11(4)$ & $2(5)$ & $5(9)$ \\
\hline \multicolumn{4}{|l|}{ Nationality } \\
\hline Germany & $213(90)$ & $35(92)$ & $52(94)$ \\
\hline Austria & $1(0.3)$ & - & - \\
\hline Croatia & $1(0.3)$ & - & - \\
\hline Greece & $1(0.3)$ & - & - \\
\hline Italy & $2(1)$ & - & - \\
\hline Missing & $19(8)$ & $3(8)$ & $3(6)$ \\
\hline \multicolumn{4}{|l|}{ Religion } \\
\hline Roman Catholic & $101(43)$ & $18(47)$ & $22(40)$ \\
\hline Protestant & $89(38)$ & $12(32)$ & $24(44)$ \\
\hline Muslim & - & - & - \\
\hline None & $43(18)$ & $6(16)$ & $8(14)$ \\
\hline New apostolic & $2(0.5)$ & $1(2.5)$ & $1(2)$ \\
\hline Buddhist & - & $1(2.5)$ & - \\
\hline Missing & $2(0.5)$ & - & - \\
\hline \multicolumn{4}{|l|}{$\begin{array}{l}\text { Main diagnosis of patient } \\
\text { assessed by relative }\end{array}$} \\
\hline Cancer & $134(57)$ & $24(63)$ & $35(64)$ \\
\hline Kidney disease & $48(20)$ & $8(21)$ & $6(11)$ \\
\hline Heart failure & $41(17)$ & $6(16)$ & $4(7)$ \\
\hline Stroke & $33(14)$ & $5(13)$ & $7(13)$ \\
\hline COPD & $19(8)$ & $3(8)$ & $4(7)$ \\
\hline Dementia & $19(8)$ & $6(16)$ & $7(13)$ \\
\hline Motor neurone disease & $2(1)$ & - & - \\
\hline
\end{tabular}


Table 2 Characteristics of next-of-kin and information about patients (Continued)

\begin{tabular}{llll}
\hline & $\begin{array}{l}\text { Main sample }(N=237) \\
\text { Number (\%) }\end{array}$ & $\begin{array}{l}\text { Interrater }(N=38) \\
\text { Number (\%) }\end{array}$ & Number (\%) \\
\hline Don't know & $5(2)$ & - & $1(2)$ \\
Something else & $51(22)$ & $12(32)$ & $13(24)$ \\
$\begin{array}{l}\text { Ward on which patient had died } \\
\text { Palliative Care Unit }\end{array}$ & $120(51)$ & $24(64)$ & $32(58)$ \\
Internal medicine and neurology & $60(25)$ & $7(18)$ & $10(18)$ \\
Intensive care unit & $57(24)$ & $7(18)$ & $13(24)$ \\
\hline
\end{tabular}

${ }^{a}$ Multiple selection was possible. Percentage rates reflect the amount of one diagnosis per sample.; $\mathrm{T} 2=$ Participants of repeated measurement

\section{Missing values}

Missing rates for items "whether health care team met overall religious spiritual needs of patient" and "whether health care team met overall religious spiritual needs of next-of-kin" were about $10 \%$ each. Missing rates for the remaining items ranged between 0.4 and $7.6 \%$.

\section{Psychometric properties}

Bartlett's test $\left(\chi^{2}(378)=2839.3 ; p<.001\right)$ and KaiserMeyer-Olkin Measure of Sampling Adequacy (0.8) indicated suitability for PCA. Therefore, a PCA with varimax rotation was conducted. As the scree plot did not show a definite "knee" point, a 7 -factor solution (Table 3) based on eigenvalues and its best conceptual fit was chosen. This solution explained $61.8 \%$ of the variance and included all core items on QOC. Items with critical values (shown in bold in Table 3) were analysed according to inclusion of items criteria (see Methods section).

\section{Inclusion of items}

Items loading on two factors were allocated according to higher loadings (items "whether patient had retained respiratory tract secretions", "whether discussion of giving fluids through a 'drip' took place", and "sensitivity of health care team after death" or content-related conformity ("time of nurses to listen and discuss the patients' condition"). The item on "whether ward was clean" was omitted from further analysis since there was no obvious content-related conformity to its factor; internal consistency of the Spiritual and emotional support subscale increased to 0.86 if it was deleted. The item on "whether patient died in the right place" was dropped from further analysis because its correlation with the Environment subscale was rather low; alpha increased to 0.81 if it was deleted. Although items on "whether patient had retained respiratory tract secretions" and "whether discussion of giving fluids through a 'drip' took place" had four critical values, they were not excluded because the expert panel rated their content consistent to their factors and the two to be indispensable components of QOC. Internal consistency for factors varied between $\alpha=0.58$ and $\alpha=0.86$ after the deletion of Items "whether ward was clean" and "whether patient died in the right place". Table 4 shows the scale analysis based on the 26-item solution. Items "whether discussion of giving fluids through a 'drip' took place", "whether discussion giving fluids through a 'drip' would have been helpful" and "emotional support to next-of-kin" showed only marginal critical values and therefore were kept for the final solution.

\section{Reliability and validity}

Overall internal consistency was good $(\alpha=0.86)$. Mean scorings of items with a rating interval scale varied between 3.0 and 3.86, for dichotomous items between 1.8 and 3.9 (Table 3). ICC (1) for interrater reliability was $0.79(\mathrm{CI95 \%}=0.6-0.9 ; \mathrm{F}(37,38)=8.5, p<.001)$. ICC $(1,2)$ for test-retest reliability was 0.85 (CI95\% = $0.8-0.9 ; \quad \mathrm{F}(54,54)=11.9, \quad p<.001)$. Coefficients for convergent validity showed a medium correlation between POS and CODE-GER $(r=-0.41, p<.001)$.

\section{Correlation between Total-score, subscales and items of overall impressions}

Mean Total-Score was 85.69 (SD $=14.17$; range $=25-$ 104). Correlations between items of overall impression and Total-Score were weak to moderate $(\mathrm{r} / \mathrm{rs}=0.36-0.67$; $p<.01$ ). Concerning the subscales, factor 1 (support and time of doctors and nurses) showed the highest correlation $(r=0.72 ; p<.01)$ with items of overall impression, factor 6 (presence of symptoms) the lowest $(\mathrm{rs}=-0.02)$ (Table 5).

\section{Difficulty of questionnaire, strain caused by assessment and time for filling out}

Difficulty of the questionnaire was rated rather low $(\mathrm{M}=2.19 ; \mathrm{SD}=2.4 ;$ range $=0-10) ;$ and mean strain caused by the assessment was $4.05 \quad(\mathrm{SD}=3.05$; range $=0-10)$. Mean duration of the assessment was 
Table 3 Item and Scale characteristics after PCA with varimax rotation

\begin{tabular}{|c|c|c|c|c|c|c|c|c|c|c|c|}
\hline \multirow[b]{2}{*}{$\begin{array}{l}\text { Subcales and short description } \\
\text { of items }\end{array}$} & \multirow[b]{2}{*}{ M } & \multirow[b]{2}{*}{ SD } & \multirow[b]{2}{*}{$\begin{array}{l}\text { Cronbachs'Alpha if item } \\
\text { deleted per scale }\end{array}$} & \multirow[b]{2}{*}{$\begin{array}{l}\text { Item Scale } \\
\text { Correlation }\end{array}$} & \multicolumn{7}{|c|}{ Factor Loadings } \\
\hline & & & & & F 1 & F2 & F 3 & F 4 & F 5 & F 6 & F 7 \\
\hline
\end{tabular}

\section{Support and time of doctors}

and nurses

$a=0.85 ; 14.6 \%$ Variance explained

\begin{tabular}{|c|c|c|c|c|c|c|}
\hline $\begin{array}{l}\text { Nursing care - medicines and } \\
\text { comfortable position }\end{array}$ & 3.8 & 0.6 & 0.82 & 0.68 & 0.73 & \\
\hline $\begin{array}{l}\text { Nursing care- personal care } \\
\text { needs }\end{array}$ & 3.7 & 0.7 & 0.82 & 0.68 & 0.72 & \\
\hline Confidence and trust in doctors & 3.6 & 0.9 & 0.83 & 0.57 & 0.67 & \\
\hline $\begin{array}{l}\text { Time of doctors to listen and } \\
\text { discuss the patient's condition }\end{array}$ & 3.5 & 0.9 & 0.82 & 0.69 & 0.66 & \\
\hline $\begin{array}{l}\text { Whether } \mathrm{HCT} \text { did all they could } \\
\text { to relieve pain }\end{array}$ & 3.9 & 0.5 & 0.84 & 0.54 & 0.62 & \\
\hline $\begin{array}{l}\text { Whether HCT did all they could } \\
\text { to control respiratory tract } \\
\text { secretions }\end{array}$ & 3.6 & 0.9 & 0.85 & 0.41 & 0.59 & \\
\hline Confidence and trust in nurses & 3.7 & 0.8 & 0.84 & 0.51 & 0.56 & \\
\hline $\begin{array}{l}\text { Whether } \mathrm{HCT} \text { did all they could } \\
\text { to relieve restlessness }\end{array}$ & 3.6 & 0.9 & 0.83 & 0.56 & 0.47 & \\
\hline $\begin{array}{l}\text { Time of nurses to listen and } \\
\text { discuss the patients' condition }\end{array}$ & 3.5 & 0.8 & 0.83 & 0.57 & 0.40 & 0.48 \\
\hline \multicolumn{7}{|l|}{$\begin{array}{l}\text { Spiritual and emotional } \\
\text { upport } \\
=0.82 ; 10.6 \% \text { Variance explained }\end{array}$} \\
\hline $\begin{array}{l}\text { Whether HCT met overall } \\
\text { religious spiritual needs for } \\
\text { patient }\end{array}$ & 3.3 & 1.0 & 0.69 & 0.82 & & 0.84 \\
\hline $\begin{array}{l}\text { Whether HCT met overall } \\
\text { religious spiritual needs for } \\
\text { next-of-kin }\end{array}$ & 3.3 & 1.1 & 0.72 & 0.77 & & 0.81 \\
\hline Emotional support to next-of-kin & 3.4 & 0.9 & 0.80 & 0.60 & & 0.58 \\
\hline Whether ward was clean ${ }^{a}$ & 3.7 & 0.8 & 0.86 & 0.43 & & 0.50 \\
\hline
\end{tabular}

\section{Information and}

decision-making

$a=0.61 ; 8.5 \%$ Variance explained

Difficulty of explanations of the patient's condition

Involvement in decision-making

Whether discussion giving fluids

been helpful

Whether discussion of giving

4 Environment

$a=0.67 ; 8.2 \%$ Variance explained

Whether the bed area had

$\begin{array}{lll}3.6 & 0.8 & 0.37 \\ 3.5 & 0.9 & 0.54 \\ 3.5 & 1.1 & \mathbf{0 . 8 1}\end{array}$

0.65

Whether the bed area was comfortable

Whether patient died in the right place ${ }^{a}$ 
Table 3 Item and Scale characteristics after PCA with varimax rotation (Continued)

\begin{tabular}{|c|c|c|c|c|c|c|c|c|c|c|c|}
\hline \multirow[b]{2}{*}{$\begin{array}{l}\text { Subcales and short description } \\
\text { of items }\end{array}$} & \multirow[b]{2}{*}{ M } & \multirow[b]{2}{*}{ SD } & \multirow[b]{2}{*}{$\begin{array}{l}\text { Cronbachs'Alpha if item } \\
\text { deleted per scale }\end{array}$} & \multirow[b]{2}{*}{$\begin{array}{l}\text { Item Scale } \\
\text { Correlation }\end{array}$} & \multicolumn{7}{|c|}{ Factor Loadings } \\
\hline & & & & & F 1 & F2 & F 3 & F 4 & F 5 & F 6 & F 7 \\
\hline \multicolumn{12}{|l|}{$\begin{array}{l}\mathbf{5} \text { Information about dying } \\
\text { process } \\
a=0.68 ; 7.6 \% \text { Variance explained }\end{array}$} \\
\hline $\begin{array}{l}\text { Whether a discussion about } \\
\text { what to expect during the dying } \\
\text { process would have been helpful }\end{array}$ & 2.9 & 1.8 & 0.51 & 0.55 & & & & & 0.75 & & \\
\hline $\begin{array}{l}\text { Information about what to } \\
\text { expect during the dying process } \\
\text { of the patient }\end{array}$ & 2.2 & 2.0 & 0.56 & 0.52 & & & & & 0.69 & & \\
\hline $\begin{array}{l}\text { Information about the soon } \\
\text { death of the patient }\end{array}$ & 3.4 & 1.4 & 0.66 & 0.44 & & & & & 0.65 & & \\
\hline \multicolumn{12}{|l|}{$\begin{array}{l}6 \text { Presence of symptoms } \\
a=0.58 ; 6.5 \% \text { Variance explained }\end{array}$} \\
\hline Whether patient was restless & 2.8 & 1.3 & 0.30 & 0.51 & & & & & & 0.83 & \\
\hline Whether patient had pain & 3.0 & 1.3 & 0.46 & 0.40 & & & & & & 0.76 & \\
\hline $\begin{array}{l}\text { Whether patient had retained } \\
\text { respiratory tract secretions }\end{array}$ & 2.7 & 1.4 & 0.65 & 0.28 & 0.42 & & & & & 0.47 & \\
\hline \multicolumn{12}{|l|}{$\begin{array}{l}7 \text { Support at actual time of } \\
\text { death and afterwards } \\
a=0.59 ; 5.7 \% \text { Variance explained }\end{array}$} \\
\hline Support at actual time of death & 3.5 & 1.0 & & 0.43 & & & & & & & 0.76 \\
\hline Sensitivity of HCT after death & 3.9 & 0.8 & & 0.43 & 0.38 & & & & & & 0.44 \\
\hline
\end{tabular}

Range of numeric item scorings: 0 to 4 (see Table 1). Although scaling differ between items, higher values are always associated with higher quality. Values in bold were critical and have been analysed individually in order to decide on item in-/exclusion; HCT $=$ Health Care Team; ${ }^{a}=$ items were deleted after analysis

43.15 min with a maximum of $240 \mathrm{~min}$. Information for interrater and $\mathrm{T} 2$ is shown in Table 6.

\section{Discussion}

We performed translation, cultural adaptation and psychometric validation of the CODE questionnaire for the German setting. Participants of this study were nextof-kin, mostly husband/wife/partner or children of the deceased patient, similar to previous $\mathrm{CODE}^{\mathrm{TM}}$ or ECHOD studies [7, 27]. CODE-GER showed good psychometric properties. Content validity was achieved through the standardized translation process and cognitive interviews with next-of-kin, which led to minimal adaptions. Although overall internal consistency was relatively high, it varied between factors from satisfactory to good. However, as all factors cover meaningful contents, none of the factors were deleted from the final solution, as recommended by Schmitt [28]. Congruency of the Total-Score between two raters and over time was good; the same applies for convergent validity.

\section{Items of overall impression}

Although correlations between items of overall impression and Total-Score were moderate, none of them had consistent correlations with all factors. Thus, the sole use of these items is not recommended.

\section{Comparison with previous data}

The German and English versions of the CODE questionnaire are identical regarding the content and number of items referring to QOC, but they differ in the coding system of answering options, number of items used for scale formation and the number of subscales. While the English version includes 12 of its 28 core items distributed on 3 key composite scales ("Environment", "Care" and "Communication"), the German version includes 26 of its 28 core items distributed on 7 subscales to form the TotalScore (Table 4). Consequently, the ranges of the TotalScore differ between the English and the German version. Furthermore, the only identical subscale between the two versions is the Environment subscale. Herein, internal consistencies of the subscales are comparable (CODE-GER $\alpha=0.81)$; $\operatorname{CODE}^{\mathrm{TM}} \alpha=0.89$ ) [7].

\section{Strengths of the study}

High research quality was achieved by following strict translation and research guidelines. To date $\operatorname{CODE}^{\mathrm{TM}}$ data had been analysed on the basis of a priori assumptions on the relationship between items. A strength of this study was the use of PCA to reveal the underlying structure of the questionnaire without a priori assumptions and to reduce data, ensuring that the most important items were displayed. 
Table 4 Final scale analysis (after omission of Items "whether ward was clean" and "Whether patient died in the right place")

\begin{tabular}{|c|c|c|}
\hline \multirow[b]{2}{*}{ Subscales and short description of items } & \multicolumn{2}{|c|}{ Overall Cronbach's Alpha $=0.86$} \\
\hline & $\begin{array}{l}\text { Cronbachs'Alpha if item } \\
\text { deleted per scale }\end{array}$ & $\begin{array}{l}\text { Ite } \\
\text { Co }\end{array}$ \\
\hline \multicolumn{3}{|l|}{$\begin{array}{l}1 \text { Support and time of doctors and nurses } \\
a=0.85 ; 14.6 \% \text { Variance explained }\end{array}$} \\
\hline Nursing care - medicines and comfortable position & 0.82 & 0.6 \\
\hline Nursing care - personal care needs & 0.82 & 0.6 \\
\hline Confidence and trust with the doctors & 0.83 & 0.5 \\
\hline $\begin{array}{l}\text { Time of doctors to listen and discuss the patient's } \\
\text { condition }\end{array}$ & 0.82 & 0.6 \\
\hline Whether HCT did all they could to relieve pain & 0.84 & 0.5 \\
\hline $\begin{array}{l}\text { Whether HCT did all they could to control } \\
\text { respiratory tract secretions }\end{array}$ & 0.85 & 0.4 \\
\hline Confidence and trust in nurses & 0.84 & 0.5 \\
\hline $\begin{array}{l}\text { Whether } \mathrm{HCT} \text { did all they could to relieve } \\
\text { restlessness }\end{array}$ & 0.83 & 0.5 \\
\hline Time of nurses to listen and discuss the patients' & 0.83 & \\
\hline
\end{tabular}

\section{Spiritual and emotional support}

$a=0.86 ; 10.6 \%$ Variance explained

Whether HCT met overall religious spiritual needs of patient

Whether HCT met overall religious spiritual needs

Emotional support to next-of-kin

3 Information and decision-making

$a=0.61 ; 8.5 \%$ Variance explained

Difficulty of explanations about the patient's

Whether discussion giving fluids through a 'drip'

\section{Environment}

$a=0.81 ; 8.2 \%$ Variance explained

Whether the bed area had adequate privacy

Whether the bed area was comfortable

\section{Information about dying process}

$a=0.68 ; 7.6 \%$ Variance explained

Whether a discussion about what to expect during

Information about what to expect during the dying

process of the patient

\section{Presence of symptoms}

$a=0.58 ; 6.5 \%$ Variance explained

Whether patient was restless 
Table 4 Final scale analysis (after omission of Items "whether ward was clean" and "Whether patient died in the right place") (Continued)

\begin{tabular}{|c|c|c|}
\hline \multirow[b]{2}{*}{ Subscales and short description of items } & \multicolumn{2}{|c|}{ Overall Cronbach's Alpha $=0.86$} \\
\hline & $\begin{array}{l}\text { Cronbachs'Alpha if item } \\
\text { deleted per scale }\end{array}$ & $\begin{array}{l}\text { Item Scale } \\
\text { Correlation }\end{array}$ \\
\hline \multicolumn{3}{|c|}{$\begin{array}{l}7 \text { Support at actual time of death and afterwards } \\
a=0.59 ; 5.7 \% \text { Variance explained }\end{array}$} \\
\hline Support at actual time of death & & 0.43 \\
\hline Sensitivity of HCT after death & & 0.43 \\
\hline
\end{tabular}

Values in bold were critical and have been analysed individually in order to decide on item in-/exclusion; HCT = Health Care Team

The response rate of this study indicates feasibility of the opt-in model, although low, but similar to previous ECHO-D or $\mathrm{CODE}^{\text {тा }}$ studies using opt-out models [7, $27,29,30]$. The results for questionnaire difficulty and assessment strain were also comparable to a previous study [6]. The above results point out the feasibility of the questionnaire and support previous study results showing that next-of-kin are capable of evaluating the care of the dying patient.

\section{Limitations}

That said, it should be remembered that information on characteristics of non-responders such as socioeconomic status was not available. Socioeconomic status might have both an impact on response as well as on difficulties and perceived strains. The non-responders may feel more burdened after their relative's death than the participating study population. Thus, non-responders may have rated the questionnaire as more emotionally strainful than the study sample. Further limitations need to be considered when interpreting the results of the study. In addition, it is difficult to interpret test-retest reliability as it is not clear, whether the assessment of quality of care is a rather stable or unstable construct in an interval of 8 weeks. It is debatable whether the sample was representative of the hospital population. Most participants were German (89\%) and, similar to previous findings, women with Christian affiliation [29]. As approximately $17 \%$ of patients in Germany have a migrant background and 5\% of the German population are Muslim [31, 32], the low participation rate of these groups might indicate a cultural obstacle, either in caring of these patients and their next-of-kin or in our recruitment method.

Further research is necessary to determine whether specific items are more essential for the Total-Score than others. Moreover, cut-off values which indicate poor, moderate or high quality of care would add practical value.

As not all significant decisions for the final CODEGER version were exclusively based on statistical values the factor solution needs to be examined in further studies. Therefore, we would recommend future studies to apply confirmatory factor analysis to quantify the goodness of fit of our factorial solution.

Table 5 Correlations between overall impression items and the subscales as well as the Total-Score

\begin{tabular}{|c|c|c|c|c|c|c|c|c|c|c|}
\hline & & & \multicolumn{7}{|c|}{ Subscales and Total-Score } & \multirow[b]{2}{*}{ Total-Score } \\
\hline & & & 1 & 2 & 3 & 4 & 5 & 6 & 7 & \\
\hline $\begin{array}{l}\text { Overall items; numbering } \\
\text { corresponding to CODE-GER }\end{array}$ & & $\mathrm{N}$ & & & & & & & & \\
\hline $27 a[1]$ & $\begin{array}{l}\text { Whether patient was treated } \\
\text { with respect and dignity by } \\
\text { doctors }\end{array}$ & 212 & $0.51^{* *}$ & $0.39^{* *}$ & $0.24^{* *}$ & $0.14^{*}$ & $0.14^{*}$ & 0.09 & $0,53^{* *}$ & $0.46^{* *}$ \\
\hline 27b [1] & $\begin{array}{l}\text { Whether patient was treated } \\
\text { with respect and dignity by } \\
\text { nurses }\end{array}$ & 223 & $0.49^{* *}$ & $0.35^{* *}$ & $0.14^{*}$ & $0.17^{*}$ & 0.22 & $0.16^{*}$ & $0.23^{* *}$ & $0.36^{* *}$ \\
\hline $28[2]$ & $\begin{array}{l}\text { Whether next-of-kin was } \\
\text { adequately supported }\end{array}$ & 230 & $0.44^{* *}$ & $0.38^{* *}$ & $0.36^{* *}$ & $0.14^{*}$ & $0.39^{* *}$ & -0.02 & $0.56^{* *}$ & $0.44^{* *}$ \\
\hline 29 [1] & $\begin{array}{l}\text { Whether next-of-kind would } \\
\text { recommend ward to } \\
\text { family/friends }\end{array}$ & 227 & $0.72^{* *}$ & $0.57^{* *}$ & $0.32^{* *}$ & $0.44^{* *}$ & $0.29^{* *}$ & $0.15^{*}$ & $0.63^{* *}$ & $0.67^{* *}$ \\
\hline
\end{tabular}

1 = Pearson-Moment-Correlation; 2 = Spearman's rank correlation coefficient; ${ }^{*} p<0.05 ;{ }^{* *} p<0.01$; subscales: (1) support and time of doctors and nurses, (2) spiritual and emotional support, (3) information and decision-making, (4) environment, (5) information about dying process, (6) symptom presence, (7) support at actual time of death and afterwards 
Table 6 Time for filling out, difficulty and strain caused by assessment

\begin{tabular}{lllll}
\hline & N & M & SD & Range \\
\hline Time for filling out - Main Sample & 229 & 43.2 & 34.8 & $10-240$ \\
Time for filling out - Interrater & 38 & 34.9 & 22.6 & $10-120$ \\
Time for filling out - T2 & 55 & 27.8 & 18.7 & $8-90$ \\
Difficulty of the questionnaire - Main sample & 235 & 2.2 & 2.4 & $0-10$ \\
Difficulty of the questionnaire - Interrater & 38 & 2.0 & 2.0 & $0-8$ \\
Difficulty of the questionnaire - T2 & 54 & 2.3 & 2.4 & $0-10$ \\
Strain caused by assessment - Main sample & 235 & 4.1 & 3.2 & $0-10$ \\
Strain caused by assessment - Interrater & 38 & 3.6 & 3.4 & $0-10$ \\
Strain caused by assessment - T2 & 54 & 3.4 & 3.4 & $0-10$ \\
\hline
\end{tabular}

$\mathrm{T} 2$ = Participants of repeated measurement

\section{Conclusion}

This study is the first translation and validation of $\mathrm{CODE}^{\mathrm{rm} .}$ in another language. Correspondingly, it is the first examination of the construct of $\mathrm{CODE}^{\mathrm{TM}}$ in a different population. The results from the present study offer confirmation that CODE-GER is a reliable and valid instrument. Moreover, our study shows that by including 26 of 28 items into the psychometric analysis, 7 subscales emerge which considerably increase the informative value of the original CODE-Questionnaire. Our study therefore not only provides the first validated tool in German language to assess QOC of the dying in last few days. It also presents an advancement of the original questionnaire, increasing its potential for further surveys and research. Future studies are recommended applying confirmatory factor analysis to quantify the goodness of fit of our factorial solution. CODE-GER (additional file 1) is now ready to assess QOC of the dying and to identify areas for improvement, which then can lead to the development of purposive interventions.

\section{Supplementary information}

Supplementary information accompanies this paper at https://doi.org/10. 1186/s12955-020-01473-2.

Additional file 1. CODE-GER Questionnaire (in English language) with the five thematically arranged sections from the original CODE TM in order to facilitate the completion of the questionnaire for relatives.

\footnotetext{
Abbreviations

CODE: Care of the Dying Evaluation; CODE-GER: Care of the Dying Evaluation - German; EORTC: European Organisation for Research and Treatment of Cancer; POS: Palliative care Outcome Scale; ICC: Inter/Intra Class Correlation; M: Mean; SD: Standard Deviation; PC: Palliative care; QOC: Quality of Care; QoDD: Quality of Death and Dying; ECHO-D: Evaluation Care and Health Outcomes; MZ: Mainz; E: Erlangen; T1: First measurement point; T2: Second measurement point; PCA: Principal component analysis; r: Pearson's correlation coefficient; rs: Spearman's rank correlation coefficient; $\mathrm{Cl}$ : Confidence interval
}

Acknowledgements

We gratefully thank all next-of-kin for their participation.
We thank the medical directors at the two study centres and the responsible physicians for their support.

We thank the Palliative Care Institute Liverpool for the provision of CODE ${ }^{\mathrm{TM}}$ and its user guide. Please contact Catriona R. Mayland (c.r.mayland@sheffield. ac.uk) for advice and permission to use CODE ${ }^{\mathrm{TM}}$.

We thank Catriona Mayland and Dagny Haugen for their cooperation and advice. Their support was most helpful and appreciated.

We thank Irene Schmidtmann for giving us statistical advice.

\section{Declarations}

The report met the criteria of "good practice in the conduct and reporting of survey research" [33].

\section{Authors' contributions}

A.R.V.' organized study conduction in Mainz, analysed data and drafted the manuscript. S.S ${ }^{1}$. co-wrote the grant application, developed the study design, provided critical comments on drafts of the manuscript and approved the final version. M.H. took part in the development of the study design, organized study conduction in Erlangen, analysed data provided critical comments on drafts of the manuscript and approved the final version. S.G. organized study conduction in Mainz, provided critical comments on drafts of the manuscript and approved the final version. S.S.M. took part in the development of the study design, provided critical comments on drafts of the manuscript and approved the final version. A.S. contributed to data analysis, provided critical comments on drafts of the manuscript and approved the final version. C.G. contributed to data interpretation, provided critical comments on drafts of the manuscript and approved the final version. C.O. developed the study design, provided critical comments on drafts of the manuscript and approved the final version. M.W. wrote the grant application, developed the study design, provided critical comments on drafts of the manuscript and approved the final version. 'Both authors contributed equally to this work. The author(s) read and approved the final manuscript.

\section{Funding}

This project was supported by "Deutsche Forschungsgemeinschaft" (DFG) [WE 561312-1] under grant number 623286. The funder had no role in the design and implementation of this study, in the collection, analysis or interpretation of the data; or in the preparation of the manuscript.

\section{Availability of data and materials}

CODE-GER may be obtained from the authors of this study. The datasets used and/or analysed during the current study are available from A.R.V. or M.H. on reasonable request.

Ethics approval and consent to participate

All ethical issues were addressed. This study was conducted with the approval of the local ethics committees at both institutions (Mainz: Landesärztekammer Rheinland/Pfalz: 837.331 .3 (901 6-F), 3rd of December 2013; Erlangen: Ethik-Kommission der Medizinischen Fakultät, 14th of April 2014). Written informed consent was obtained from next-of-kin.

\section{Consent for publication}

Not applicable.

\section{Competing interests}

The authors declare that they have no competing interests.

\section{Author details}

${ }^{1}$ Interdisciplinary Palliative Care Unit, III. Department of Medicine, University Medical Center of the Johannes Gutenberg University of Mainz, Langenbeckstr.1, 55131 Mainz, Germany. ${ }^{2}$ Hannover Medical School, Institute for General Practice, Carl-Neuberg-Straße 1, 30625 Hannover, Germany. ${ }^{3}$ Friedrich-Alexander-Universität Erlangen- Nürnberg (FAU), Department of Palliative Medicine, CCC Erlangen -EMN, Krankenhausstraße 12, 91054 Erlangen, Germany. ${ }^{4}$ Centre for Educational Research and Teacher Training (PLAZ), Paderborn University, Warburger Straße 100, 33098 Paderborn, Germany. 
Received: 4 April 2019 Accepted: 1 July 2020

Published online: 22 September 2020

\section{References}

1. Saunders C. The evolution of palliative care. J R Soc Med. 2001;94:430-2.

2. Morin L, Aubry R, Frova L, et al. Estimating the need for palliative care at the population level: a cross-national study in 12 countries. Palliat Med. 2017;31: 526-36.

3. Virdun C, Luckett T, Lorenz $\mathrm{K}$, et al. Dying in the hospital setting: a metasynthesis identifying the elements of end-of-life care that patients and their families describe as being important. Palliat Med. 2017;31:587-601.

4. Teno JM. Measuring end-of-life care outcomes retrospectively. J Palliat Med. 2005:8(Suppl 1):S42-9.

5. Addington-Hall J, McPherson C. After-death interviews with surrogates/ bereaved family members: some issues of validity. J Pain Symptom Manag. 2001;22:784-90.

6. Heckel M, Bussmann S, Stiel S, Weber M, Ostgathe C. Validation of the German version of the quality of dying and death questionnaire for informal caregivers (QODD-D-Ang). J Pain Symptom Manag. 2015;50:402-13.

7. Mayland CR, Lees C, Germain A, et al. Caring for those who die at home: the use and validation of 'Care of the dying Evaluation' (CODE) with bereaved relatives. BMJ Support Palliat Care. 2014:4:167-74.

8. Kupeli N, Candy B, Tamura-Rose G, Schofield G, Webber N, Hicks SE, et al. Tools measuring quality of death, dying, and care, completed after death: systematic review of psychometric properties. Patient. 2019;12:183-97.

9. Dewolf $\mathrm{L}$, Koller M, Velikova $\mathrm{G}$, et al. EORTC quality of life group translation procedure. 2009.

10. Bausewein C, Fegg M, Radbruch $L$, et al. Validation and clinical application of the German version of the palliative care outcome scale. J Pain Symptom Manag. 2005:30:51-62.

11. Mai SS, Gerlach C, Schmidtmann I, et al. Are repeated self-reports of psychological variables feasible for patients near the end of life at a palliative care unit? J Palliat Med. 2018;21:1005-10.

12. Stiel $S$, Matthes $M$, Bertram $L$, et al. Validation of the new version of the minimal documentation system (MIDOS) for patients in palliative care: the German version of the Edmonton symptom assessment scale (ESAS). Schmerz. 2010:24:596-604.

13. Lienert GA, Raatz U. Testaufbau und Testanalyse [test construction and test analysis]. 7th ed. Beltz: Weinheim; 1998.

14. Marshall A, Altman DG, Royston P, Holder RL. Comparison of techniques for handling missing covariate data within prognostic modelling studies: a simulation study. BMC Med Res Methodol. 2010;10:7.

15. Graham JW. Missing data analysis: making it work in the real world. Annu Rev Psychol. 2009;60:549-76.14

16. Kaiser HF. A note on Guttman's lower bound for the number of common factors. Br J Math Stat Psychol. 1961;14:1-2.

17. Cattell RB. The scree test for the number of factors. Multivar Behav Res. 1966;1:245-76.

18. Leech NL, Barrett KC, Morgan GA. SPSS for Intermediate Statistics, Use and Interpretation. 2th ed. New Jersey: Lawrence Erlbaum Associates Inc.; 2005.

19. Osborne JW. Best practices in exploratory factor analysis: CreateSpace Independent Publishing Platform; 2014.

20. Cronbach $\amalg$ J. Coefficient alpha and the internal structure of tests. Psychometrika. 1951;16:297-334.

21. Bland JM, Altman DG. Statistics notes: Cronbach's alpha. Bmj. 1997:314:572.

22. Shrout PE, Fleiss JL. Intraclass correlations: uses in assessing rater reliability. Psychol Bull. 1979;86:420

23. Mandrekar JN. Measures of interrater agreement. J Thorac Oncol. 2011;6:6-7.

24. Koo TK, Li MY. A guideline of selecting and reporting intraclass correlation coefficients for reliability research. J Chiropr Med. 2016;15:155-63.

25. Weber JC, Lamb DR. Statistics and research in physical education. Mosby Distributed by Kimpton, 1970.

26. Corp. RI. IBM SPSS Statistics for Windows, Version 24.0. Armonk, NY: IBM Corp; 2015

27. Mayland CR, Mulholland H, Gambles M, Ellershak J, Stewart K. How well do we currently care for our dying patients in acute hospitals: the views of the bereaved relatives? BMJ Support Palliat Care. 2017;7(3):316-25.

28. Schmitt N. Uses and abuses of coefficient alpha. Psychol Assess. 1996:8:350.

29. Mayland CR, Williams EM, Ellershaw JE. Assessing quality of care for the dying: the development and initial validation of a postal self-completion questionnaire for bereaved relatives. Palliat Med. 2012;26:897-907.
30. Mayland C, McGlinchey T, Gambles M, Mulholland H, Ellershaw J. Quality assurance for care of the dying: engaging with clinical services to facilitate a regional cross-sectional survey of bereaved relatives' views. BMC Health Serv Res. 2018;18(1):761.

31. Blum K, Steffen P. Kultursensibilität der Krankenhäuser in NordrheinWestfalen [Cultural sensitivity in hospitals in North Rhine-Westphalia]. Düsseldorf: Deutsches Krankenhausinstitut; 2012.

32. Haug S, Müssig S, Stichs A. Muslimisches Leben in Deutschland. [Muslim Life in Germany] Bundesamt für Migration und Flüchtlinge; 2009

33. Kelley K, Clark B, Brown V, Sitzia J. Good practice in the conduct and reporting of survey research. Int J Qual Health Care. 2003;15:261-6.

\section{Publisher's Note}

Springer Nature remains neutral with regard to jurisdictional claims in published maps and institutional affiliations.
Ready to submit your research? Choose BMC and benefit from:

- fast, convenient online submission

- thorough peer review by experienced researchers in your field

- rapid publication on acceptance

- support for research data, including large and complex data types

- gold Open Access which fosters wider collaboration and increased citations

- maximum visibility for your research: over $100 \mathrm{M}$ website views per year

At BMC, research is always in progress.

Learn more biomedcentral.com/submissions 